\title{
Genetic effects on heartwood color variation in Cryptomeria japonica
}

\author{
Naoko Miyamoto' ${ }^{1}$ Kazuya lizuka², Jin'ya Nasu ${ }^{1}$ and Hiroo Yamada ${ }^{3}$
}

\begin{abstract}
${ }^{1}$ Tohoku Regional Breeding Office, Forest Tree Breeding Center, Forestry and Forest Products Research Institute, Forest Research and Management Organization, 95 Osaki, Takizawa, Iwate 020-0621, Japan

${ }^{2}$ School of Agriculture, Utsunomiya University, 350 Minemachi, Utsunomiya, Tochigi 321-8505, Japan

${ }^{3}$ Forest Tree Breeding Center, Forestry and Forest Products Research Institute, Forest Research and Management Organization, 3809-1 Ishi, Juo, Hitachi, Ibaraki 319-1301, Japan
\end{abstract}

Corresponding Author: Naoko Miyamoto, E-mail: naoruko@affrc.go.jp

\section{Abstract}

To obtain fundamental and useful information regarding heartwood color traits in Japanese cedar, the validity of using $L^{*}$ index for expressing heartwood color and genetic and environmental influences on heartwood color were analyzed using 118 clones with 303 individuals aged approximately 30 years. As for three clones with typical reddish and blackish heartwood, relationships between heartwood color and moisture/ potassium content, which were pointed out as ones of the causative agents of blackish heartwood, and the color change after approximately 20 years of conservation were investigated.

Based on the continuity, width range, and standard deviation of each index of $L^{*} a^{*} b^{*}$ data, $L^{*}$ was found out to be an appropriate index to express heartwood color in this species. $L^{*}$ values significantly differed between clones. A moderately high repeatability of clones was detected in $L^{*}$ value. Spatial autocorrelation analysis also showed a stronger effect genetically than environmentally. Moisture and potassium contents significantly differed between two groups of reddish and blackish heartwood. Therefore, the absorption and accumulation of water and potassium into trunk may be genetically regulated. As for the $L^{*}$ value of heartwood color after approximately 20 years of conservation, the difference between two groups was still significant, but the lightness in blackish heartwood increased such that the difference was greatly reduced.

Keywords: Japanese cedar, heartwood color, $L^{*} a^{*} b^{*}$ color sytem, spatial autocorrelation, potassium

\section{Introduction}

The heartwood color of Japanese cedar (Cryptomeria japonica D. Don), also known as Sugi, is quite variable, ranging from reddish to blackish. A tree or wood with a reddish heartwood color is called "Akajin" ("aka" means "red" and "jin" means "heart"), whereas a tree or wood with a blackish heartwood color is called "Kurojin" ("kuro" means "black"; Kitamura, 1962; Morikawa et al., 1996). Images of typical "Akajin" and "Kurojin" specimens are depicted in Figure 1.

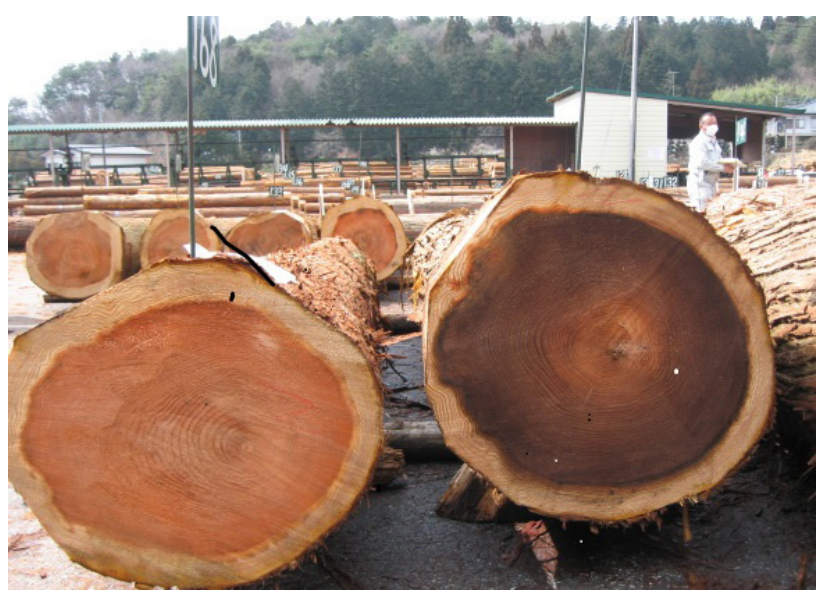

Figure 1

Photos of typical "Akajin" (left) and "Kurojin" (right) specimens

It is empirically known that there is a relation between heartwood color and heartwood moisture content and that the moisture content of reddish heartwood is low, whereas that of blackish heartwood is high (Yazawa 1964; Fujiwara and 
Iwagami 1988; Kawazumi et al. 1991; Hirakawa et al. 2003a, b). Cracking or bending is more likely to occur in heartwood when not dried enough, and consequently the strength of the wood for construction will be deficient unless sufficient drying has occurred. The high moisture content and related high transportation and drying costs of "Kurojin" contribute to its lower valuation. In addition, "Akajin" is more appreciated than "Kurojin" for esthetic reasons. When wood is used for traditional construction and not as laminated wood, particularly when it is used in a way that makes the heartwood color observable, the market valuation of "Kurojin" becomes lower than that of "Akajin" because of its less appealing appearance (Kuroda, 2006; Ohba et al., 1977).

Some reports on "Kurojin" formation have stated that potassium (K) within the heartwood is also related to heartwood color (Morikawa et al. 1996; Oda et al. 1994; Kubo and Ataka 1998; Nishizawa et al. 2003). Potassium in soil that moves from sapwood to heartwood is considered to contribute to the variation in heartwood color (Nakada 2007). Some variations in Kurojin exist: in some cases, the blackish part constitutes the entire heartwood; in others, one part of the heartwood may be black or the boundary between heartwood and sapwood may be irregular, and color irregularity may also exist. Abe et al. (1994) identified potassium bicarbonate as a causative agent of Kurojin in cases where the blackish part constitutes the whole heartwood, by giving the heartwood a weakly alkaline condition.

Because wood color affects the drying process adopted and the potential future utilization of the wood, as detailed above, wood color is economically important. Accordingly, various studies on the range of colors and the relationship of color with moisture content have been compiled (Fujiwara and Iwagami 1988; Hirakawa et al. 2003a, b; Kawazumi et al. 1991). The heartwood color of Japanese cedar has been conventionally expressed in terms of three values in the $L^{*} a^{*} b^{*}$ color system. In several cases, the $L^{*}$ value is used as an index for the evaluation of heartwood color. It is generally accepted that the $L^{*}$ value representing lightness most appropriately indicates the differences in heartwood color (Kubo and Ataka 1998; Morikawa et al. 1996; Oda et al. 1994). However, the validity of expressing wood color using $L^{*}$ values remains scientifically unverified.

As stated above, moisture content and potassium content in heartwood are considered to be related to heartwood color. It is not clearly understood, however, whether trees with blackish heartwood tend to take up more water/potassium than other trees or whether they were simply planted in soil that contained more water/potassium. In other words, the relative importance of genetic vs. environmental effects on the formation of blackish heartwood is unknown. While some reports have revealed that heartwood color is genetically controlled and that clear differences between clones exist (Kurinobu et al. 1992; Nakada 2007), another report has indicated that Japanese cedar is affected by environmental factors such as soil water and type (Kansai Regional Breeding Office, Forest Tree Breeding Center 1977). Several past reports on the wood color of Japanese cedar have concentrated on some undefined individuals within the species, overlooking the differences between genetically identical varieties (hereafter referred to as "clones"). In addition, the researched sites were not ecologically uniform, except in a few reports (Kurinobu, 1992; Hirakawa et al., 2003a, b).

"Kurojin" has no disadvantageous properties affecting its use as a building material, such as wood strength (Endo et al. 2001). Yet because an attractive color is a very appealing trait to general users, some users strongly prefer reddish woods (Kansai Regional Breeding Office, Forest Tree Breeding Center 1977; Kuroda 2006; Ohba et al. 1977). Furthermore, the color of wood after drying is more important than that before drying because it is already dried by the time it is selected and used. To date, there are no reports on the color change in heartwood of "Akajin" and "Kurojin" when stored for very long periods of time, which is an essential information for users.

Based on the background about heartwood color described above, we studied 1. The validity of expressing wood color using $L^{*}$ values, 2 . the genetic and environmental effects on heartwood color from multiple viewpoints, and 3 . heartwood color change after very long periods of time.

For these, we analyzed the heartwood color of multiple individuals from the same clones with known genetic background, grown not in the wild but in a flat nursery where we can safely assume a uniform soil environment; old nursery of Forest Tree Breeding Center (FTBC) in Mito, Japan, and some wood samples conserved.

In particular, for the validation of the color index, it is required that visual continuity is achieved when arranged by its index value. Moreover, the larger the variation and standard deviation of the index and nearer the index to the normal distribution, the better it is likely to be. Therefore, we tested the continuity, width range, standard deviation, and normality of each index of $L^{*}, a^{*}$ and $b^{*}$. As for the evaluation of genetic effects on heartwood color, we analyzed differences between clones, genetic repeatability. Genetic repeatability was separately calculated for the clones propagated by grafting and cutting as well as for all individuals to identify any effect of the propagation method. Spatial autocorrelation was also analyzed because it is possible to evaluate environmental influence by investigating whether trees planted in the same area have similar heartwood colors. In addition, when the water and potassium contents in the soil of this nursery are considered uniform, it is possible (though only indirectly) to discuss whether there is an influence of heredity on the absorption of these substances, which are thought to affect the heartwood color, depending on whether reddish and blackish heartwood specimens have different water and potassium contents. Finally, to clarify how wood color changes over very long periods of time, we assessed the color of clone specimens with reddish and blackish heartwood that had been stored for approximately 20 years. 


\section{Material and Methods}

\section{Site and origin of material}

We used the color and moisture content data published in a report on characteristic evaluation for forest tree genetic resources (Forest Tree Breeding Center, 1998) from trees planted in a clonal breeding material conservation stand (Stand No. 15 at the old Forest Tree Breeding Center in Mito, Japan). These clonal breeding materials comprises plus trees. Plus trees are individuals with excellent phenotypes in such traits as growth, stem straightness and roundness, wood quality, and resistance to disease, insects, or weather damage. As part of the plus tree selection program (Forestry Agency Guidance Department 1994), trees designated as plus trees are selected from national and private forests by local forestry or prefectural offices. The stand was located on a flat land. Clones were planted in lines at $2 \times 1.5 \mathrm{~m}$ spacing without any experimental design. Totally, $82 \%$ of clones and $82 \%$ of individuals were propagated by grafting and others by cutting. A maximum of three individuals per clone were planted. The age of trees used in the current study was approximately 30 years (ranging from 28 to 32 years). Of the 118 clones planted at Mito, 303 trees were analyzed; the others were omitted because molecular analysis revealed that they were mixtures of plural clones. Molecular analysis was performed using the copies propagated by cutting or grafting and planted at the present Forest Tree Breeding Center in Hitachi (Miyamoto et al. 2015) because the trees planted at Mito no longer exist.

Wood discs of approximately $10-\mathrm{cm}$ thickness at a height of $1.6 \mathrm{~m}$ from trees that had been cut down approximately 20 years ago were conserved until the present day. Parts of these discs were used to obtain the 5) d. potassium contents and 6) color change data.

\section{Data on wood color and moisture content in heartwood}

The data for wood color and moisture content was obtained as follows: a cross-section disk of 10-cm thickness for each tree at $1.6 \mathrm{~m}$ ground height was analyzed. The surface was previously smoothed by a disk planer under green-wood conditions. Measurements were conducted using a colorimeter (Minolta CR-300; measurement area $\varphi 8 \mathrm{~mm}$ ) and expressed in the $L^{*} a^{*} b^{*}$ color space (CIE $L^{*} a^{*} b^{*}$ (CIELAB) as specified by the International Commission on Illumination). $L^{*}$ indicates lightness, $a^{*}$ indicates the red-green axis, and $b^{*}$ indicates the yellow-blue axis. The average values for eight scattered points, avoiding obvious damages, within each heartwood sample were used for the analysis.

Moisture content of separated heartwood in a greenwood condition (MC) (\%) was measured as (Wg-Wo/Wo) x 100, where $\mathrm{Wg}$ is the weight of fresh wood and Wo is the weight of the wood after dried in an oven at $105^{\circ} \mathrm{C}$ until its weight remained unchanged.

\section{Verification of the color expressing index}

The validities of the indices for expressing wood color of Japanese cedar were tested based on continuity, width range, standard deviation, and normality.

\section{a. Continuity}

When the color is expressed by one color index, a perception of visual continuity in colors when the index is arranged by its values is required. Therefore, we arranged color values by each value of $L^{*}, a^{*}$, and $b^{*}$, respectively, and calculated the color difference between two adjoining values using the three $L^{*} a^{*} b^{*}$ values. The color difference was calculated as follows:

$$
\sqrt{\left(\Delta \mathrm{L}^{* 2}+\Delta \mathrm{a}^{* 2}+\Delta \mathrm{b}^{* 2}\right)}
$$

All color differences were summed for each of the three cases and compared. The index with the smallest color differences was regarded as the best index.

To evaluate the visual continuity of each index and to visually model its characteristics, we re-created each color from the $L^{*} a^{*} b^{*}$ values using the software Irodashi Meijin Pro for Windows ver.1.01 (Color Dream Net, 2013). We then sorted the recreated colors according to the value of each of the three indices from small to large. In addition, by fixing the values of the two other colors, the colors were similarly expressed for each of the three cases, following which the trends for the three indices were evaluated.

b. Width range, standard deviation, and normality The wider the difference and the larger the standard deviation, the easier it is to express the color differences. Therefore, the width range (difference between the biggest and smallest values) and standard deviation for each index was calculated and compared among indices. Indices with a normal distribution can be used to equally express color differences for higher and lower values. In addition, indices with a normal distribution facilitate later analysis. Therefore, we tested normality using the Shapiro-Wilk test in R software version 3.0.0 (R Core Team 2013) for each of the $L^{*} a^{*} b^{*}$ values.

Following 4) "typical Akajin" and "typical Kurojin" selection and 5) c spatial autocorrelation analysis, detailed below, we identified the most suitable index for expressing Sugi heartwood color in this validation process.

\section{"Typical Akajin" and "typical Kurojin" selection}

We selected "typical Akajin" and "typical Kurojin" specimens based on the heartwood color value for the index determined to be the most appropriate through the process described above. We defined "typical Akajin" and "typical Kurojin" clones as those having upper $25 \%$ values and lower $75 \%$ values for the index (average value for clone), respectively. Among these, we could access wood samples for three (eight individuals each) clones each of "typical Akajin" and "typical Kurojin." They were used for further analysis of 5) d. potassium content and 6) color change. 


\section{Evaluation of genetic variation in wood color}

We examined the genetic variation in wood color in three ways as detailed below.

\section{a. Differences between clones}

When differences between clones exist, the genetic effect is considered to be strong. However, the plantation used in the current study had no replications. Therefore, we used a permutation test (10,000 times) using the R package "coins" (R Core Team 2013) to determine whether the $L^{*}, a^{*}$, and $b^{*}$ values for heartwood significantly differed between clones.

\section{b. Repeatability}

Based on the variance component $\left(\sigma^{2}\right)$ and error variance components $\left(\sigma_{e}^{2}\right)$ of the clones for the $L^{*}, a^{*}$, and $b^{*}$ values, the repeatability for each clone $(R c)$ was calculated as follows:

$$
(R c)=\sigma_{c}^{2} /\left(\sigma_{c}^{2}+\sigma^{2}\right) \text {. }
$$

A high repeatability indicates a highly heritable trait. $R c$ was calculated using individuals that were propagated by grafting and those propagated by cutting separately to evaluate differences in the propagation methods, in addition to using all individuals.

\section{c. Spatial autocorrelation}

As the tested stand was located on a flat land, we can assume that it was topographically uniform. It is not known, however, whether there were subtle differences in soil fertility or water saturation within the nursery. As stated above, a maximum of three individuals for each clone were planted in a line form. Therefore, when the spatial autocorrelation analysis was conducted using data from all three individuals, environmental effects (due to variation in soil fertility or moisture) and genetic effects (due to the adjacent placement of genetically identical individuals) were evaluated concurrently. On the other hand, when we used data from one individual from each line of a clone, only the environmental effect was evaluated. Therefore, we conducted spatial autocorrelation analysis for wood color expressed by one index identified as a most suitable one using the following: (1) data from all individuals and (2) data from one individual within each clone line (simulations repeated 100 times to choose one random individual from each clone line). Subsequently, we estimated the genetic and environmental effects by comparing these results.

For analysis conditions ( 1 ) and (2), we calculated Moran's I as a measure of spatial autocorrelation (Moran, 1950). The value of I ranges from -1 to $1 . I=-1$ means that points with similar values are perfectly dispersed; $I=1$ means that points with similar values are perfectly clustered. When points with similar values are arranged randomly, I has a value close to 0 . Spatial weight was calculated using the function "nb2listw(),, and Moran's I value and its significance level were calculated using the function "moran.test()" in the spdep and tripack packages in R software version 3.0.0 (R Core Team 2013).
The detection of significant spatial autocorrelation in analysis condition (2) would indicate that the environmental effect was not negligible and that wood color was strongly affected by the planting environment. In contrast, the absence of significant spatial autocorrelation in condition (2) would indicate that the environmental effect was negligible in this nursery. Significant spatial autocorrelation in condition (1) but no significant spatial autocorrelation in condition (2) would indicate that the wood color was similar within clones, suggesting that a genetic effect on wood color exists among trees planted in a uniform environment.

d. Relationship between $L^{*} a^{*} b^{*}$ value and moisture and potassium contents

Using "typical Akajin" and "typical Kurojin" heartwood samples, we analyzed the relationship between $L^{*} a^{*} b^{*}$ values and moisture and potassium contents. Potassium contents of heartwood were measured by atomic absorption spectroscopy. To obtain ash, woody powder samples were heated with an electric muffle furnace (Advantec, FUL 220 FA). A sample amount of $1 \mathrm{~g}$ was reduced to ash at a combustion temperature of $500^{\circ} \mathrm{C}$ over a period of 24 hours. The obtained ash was dissolved with $0.1 \mathrm{~mol} / \mathrm{L}$ hydrochloric acid. Potassium content was determined with an atomic absorption photometer (Hitachi, Z-2310). The difference in the moisture and potassium contents of the heartwood between "typical Akajin" and "typical Kurojin" groups was investigated on the basis of the Wilcoxon rank sum test. A $p$-value of $<0.05$ was considered to be statistically significant.

\section{Heartwood color change for approximately 20 years of conservation}

We collected the heartwood color data of 20 years conserved discs for "typical Akajin" and "typical Kurojin." The method used was same as that used when the data was obtained approximately 20 years ago in green condition; the average values for eight scattered points avoiding obvious damages on the disc with a surface smoothed by a disk planner using a colorimeter. We then compared each three indices with those of just after logging. Correlation coefficients were also calculated.

\section{Results}

\section{Verification of the color expressing index}

a. Continuity

The summed color differences in two adjacent values arranged by each of the values of the $L^{*} a^{*} b^{*}$ index were $1,062.9$ for $L^{*}$, $2,271.0$ for $a^{*}$, and $1,440.5$ for $b^{*}$, indicating that arrangement by the $L^{*}$ value is the best method for similar colors to be closely placed. Figure 2 shows the colors expressed by the three values of $L^{*} a^{*} b^{*}$ arranged by the values for each $L^{*} a^{*} b^{*}$ index. We can also visually observe the continuity in the plot arranged by the $L^{*}$ value. Figure 3 shows the colors expressed by only one value of each of the $L^{*} a^{*} b^{*}$ values by fixing the other two indices arranged by the values for each $L^{*} a^{*} b^{*}$ index. In 

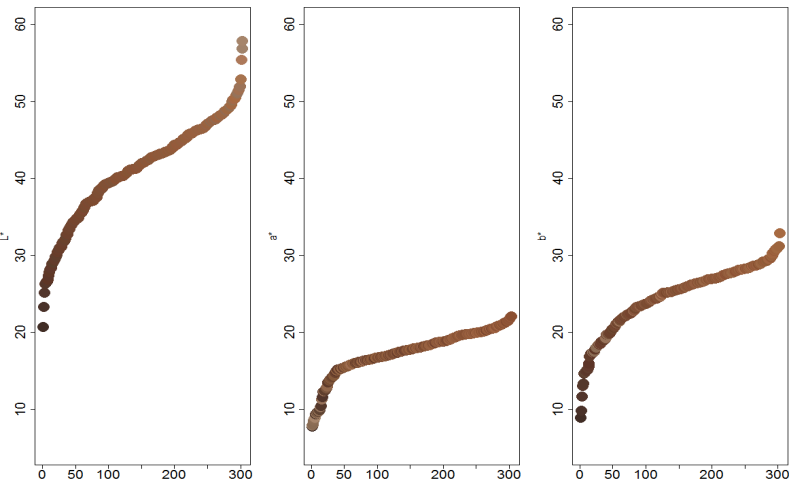

Figure 2

Colors expressed by the three values of $L^{*} a^{*} b^{*}$, arranged by the values for each $L^{*} a^{*} b^{*}$ index

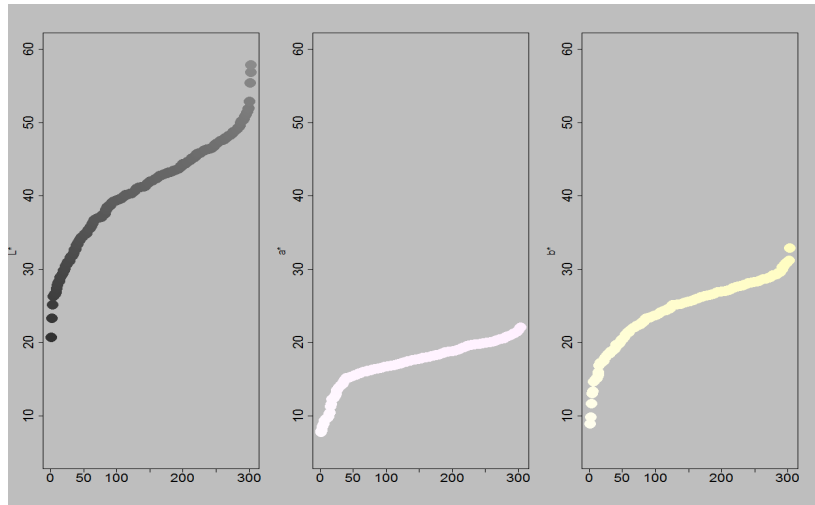

Figure 3

Colors expressed by only one value of each of the $L^{*} a^{*} b^{*}$ values by fixing the other two indices, arranged by the values for each $L^{*} a^{*} b^{*}$ index

Figure $3, L^{*}$ indicates lightness, $a^{*}$ indicates redness, and $b^{*}$ indicates yellowness, and it visually shows that the variation of $L^{*}$ is clearer than that of the other two indices.

b. Width range, standard deviation, and normality

With regard to the heartwood data for all 118 clones, the maximum (57.87) and minimum (20.74) $L^{*}$ values differed by approximately 37 points, whereas those of the $a^{*}$ and $b^{*}$ values differed by approximately 14 and 24 points, respectively. The standard deviation for $L^{*}$ for all data of 118 clones was 6.38 , whereas that for $a^{*}$ and $b^{*}$ were 2.83 and 4.14 , respectively. $L^{*}$ had the widest range and largest standard deviation among the three indices. Normality was not detected in any of the three indices according to the normality test.

Based on these findings, we concluded that $L^{*}$ index is the best for expressing Sugi heartwood color.

\section{Evaluation of genetic variation in wood color}

a. Differences between clones

Heartwood $L^{*}, a^{*}$, and $b^{*}$ values for all 118 clones and 303 individual trees are shown in Table 1 . Clones significantly differed for heartwood $L^{*}(p=0.020)$ and $a^{*}(p=0.004)$ values. For
Table 1

Heartwood $L^{*}$, $a^{*}$, and $b^{*}$ values for 118 clones consisting of 303 individual trees for "typical Akajin" and "typical Kurojin"

\begin{tabular}{|l|c|c|c|c|c|c|c|c|c|}
\hline & \multicolumn{3}{|c|}{ Total } & \multicolumn{3}{|c|}{ Typical Akajin } & \multicolumn{3}{|c|}{ Typical Kurojin } \\
\hline & $L^{*}$ & $a^{*}$ & $b^{*}$ & $L^{*}$ & $a^{*}$ & $b^{*}$ & $L^{*}$ & $a^{*}$ & $b^{*}$ \\
\hline Average & 41.19 & 17.47 & 24.71 & 49.23 & 18.4 & 29.73 & 31.18 & 14.8 & 18.61 \\
\hline $\begin{array}{l}\text { Standard } \\
\text { deviation }\end{array}$ & 6.38 & 2.83 & 4.14 & 2.19 & 1.79 & 2.01 & 2.37 & 2.85 & 2.68 \\
\hline $\begin{array}{l}\text { Coefficient of } \\
\text { variation }\end{array}$ & 0.16 & 0.16 & 0.17 & 0.04 & 0.10 & 0.07 & 0.08 & 0.19 & 0.14 \\
\hline Max & 57.87 & 22.1 & 32.91 & 52.92 & 20.35 & 32.91 & 35.58 & 18.05 & 23.11 \\
\hline Min & 20.74 & 7.77 & 8.9 & 45.84 & 15.83 & 26.7 & 28.27 & 9.72 & 14.99 \\
\hline Tree number & 303 & 303 & 303 & 8 & 8 & 8 & 8 & 8 & 8 \\
\hline Clone number & 118 & 118 & 118 & 3 & 3 & 3 & 3 & 3 & 3 \\
\hline
\end{tabular}

heartwood $b^{*}$ values, on the contrary, we did not detect a significant difference.

b. Repeatability

Rc for individuals propagated by grafting, those propagated by cutting, and all the individuals are shown in Table 2. Rc for $L^{*}$, $a^{*}$, and $b^{*}$ values for all the individuals was found to be 0.509 , 0.556 , and 0.542 . This means that wood color was a moderately heritable trait. Differences in Rc between different propagation methods were unclear; as for $L^{*}$, Rc for cutting was slightly larger than that for grafting, but was contrary in $a^{*}$ and $b^{*}$.

Table 2

Repeatability for each clone (Rc) in heartwood $L^{*}, a^{*}$, and $b^{*}$ values for trees propagated by grafting, for those propagated by cutting, and for all the individuals

\begin{tabular}{cccc}
\hline & $L^{*}$ & $a^{*}$ & $b^{*}$ \\
\hline propagated by grafting & 0.505 & 0.556 & 0.567 \\
propagated by cutting & 0.531 & 0.457 & 0.512 \\
all individuals & 0.509 & 0.542 & 0.556
\end{tabular}

c. Spatial autocorrelation

Planted positions are shown in Figure 4(a). The circles show the relative planted position for each individual, and each circle's color shows its heartwood color as expressed by the $L^{*} a^{*} b^{*}$ values. In Figure 4(b), we show one result from among 100 simulations of a randomly chosen individual from each clone. Moran's I as calculated for the $L^{*}$ value, expected value and its significance level in analysis condition (1) is shown in Table 3.

\section{Table 3}

Values of Moran's I calculated using all individuals [corresponds to Figure 4a) and one individual within each clone line (corresponds to Figure 4b); one of the results among 100 simulations] * : significance level at $5 \%$

\begin{tabular}{lcc}
\hline & using all individuals & $\begin{array}{c}\text { using one individual } \\
\text { within each clone line }\end{array}$ \\
\hline Moran's I statistic & 0.074 & -0.052 \\
Expectation & -0.0033 & -0.0085 \\
p-value & $0.013^{*}$ & N.S.
\end{tabular}


(a)

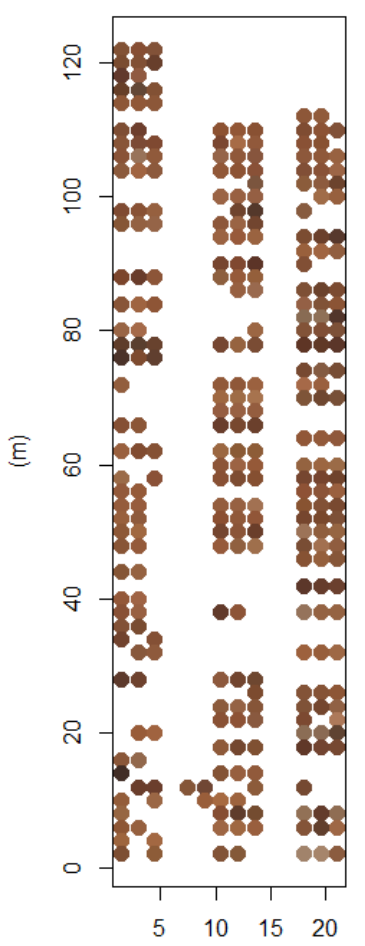

(m) (b)

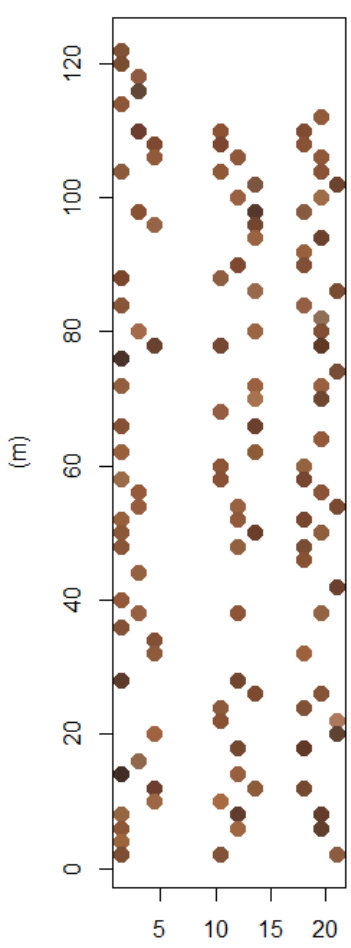

(m)

Figure 4

(a) Planted positions of all individuals and their wood colors as expressed by the obtained $L^{*} a * b *$ values.

(b) Representatives out of 100 simulations for planted positions and wood colors for one individual randomly selected from each clone line

I value was significantly different from expected value at a $5 \%$ level $(p=0.013)$. In analysis condition ( 2 ), in contrast, this was not the case: none of the results of the 100 simulations was significant. These results mean that the nursery was environmentally homogeneous enough that we can assume a uniform environment with regard to effect on wood color, and that in this uniform condition, the genetic effect was significantly strong.

d. Relationship between $L^{*} a^{*} b^{*}$ value and moisture and potassium contents

The $L^{*} a^{*} b^{*}$ data in heartwood for "typical Akajin" and "typical Kurojin" are shown in Table 1. Relationships for $L^{*} a^{*} b^{*}$ values and moisture and potassium contents in heartwood for "typical Akajin" and "typical Kurojin" are plotted in Figure 5. There was a significant difference in moisture $(p<0.01)$ and potassium ( $p<0.01)$ content in heartwood between "typical Akajin" and "typical Kurojin" trees.

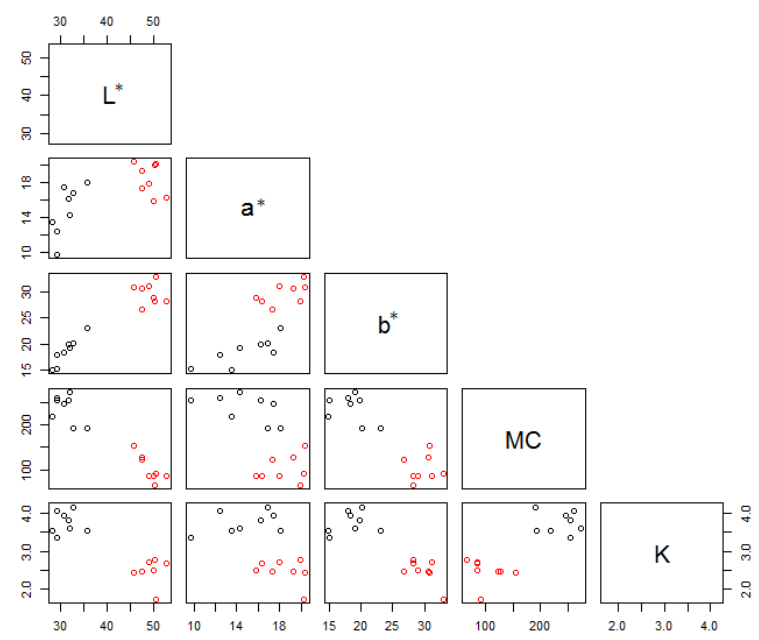

Figure 5

Relationship between the wood color values $\left(L^{*} a^{*} b^{*}\right)$, potassium content $(\mathrm{K})$ and moisture content $(\mathrm{MC})$ in heartwood for "typical Akajin" and "typical Kurojin." "Typical Akajin" and "typical Kurojin" are colored red and black, respectively
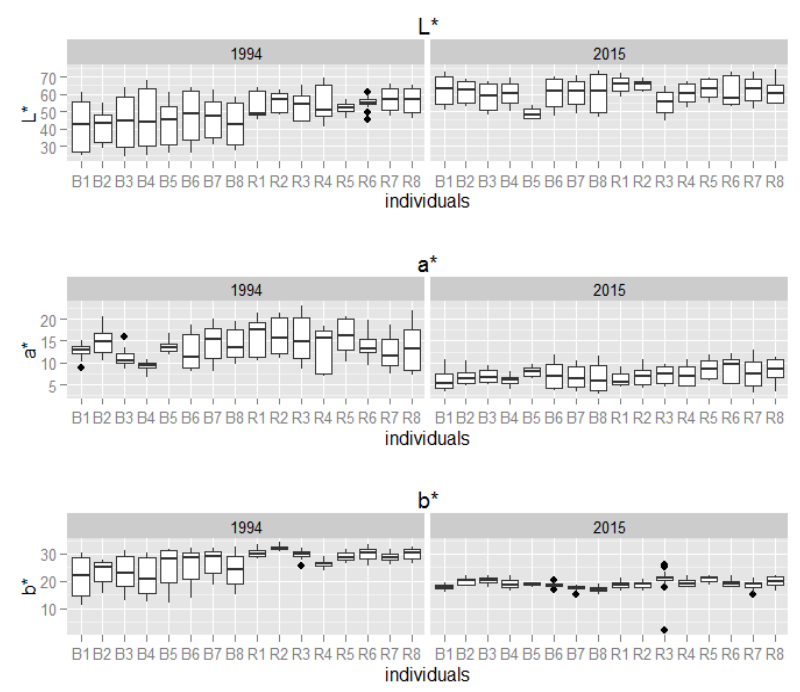

Figure 6

Heartwood color value for "typical Akajin" and "typical Kurojin" in fresh wood in 1994 and that after conservation in 2015.

B1 to B8 represent "typical Kurojin", and R1 to R8 represent to "typical Akajin"

\section{Heartwood color change after approximately 20 years of conservation}

Heartwood color values for "typical Akajin" and "typical Kurojin" in fresh wood and in wood that had been stored for approximately 20 years are shown in Figure 6. $L^{*}$ values increased, whereas $a^{*}$ and $b^{*}$ values decreased in both "typical Akajin" and "typical Kurojin" after conservation. Differences between "typical Akajin" and "typical Kurojin" in 2015 were always significant in all the three indices $(p<0.01)$, but were obviously 
decreased compared with those just after cutting in 1994. Correlation coefficient between color indices in 1994 and 2015 for $L^{*}$ and $a^{*}$ were $0.759(p<0.01)$ and $0.715(p<0.01)$, respectively, and that for $b^{*}$ was quite low $(0.063 ;$ N.S.).

\section{Discussion}

$L^{*} a^{*} b^{*}$ values in the CIELAB color space have traditionally been used to express heartwood color in C. japonica. It is generally accepted that the $L^{*}$ value representing lightness most appropriately indicates differences in heartwood color (Kubo and Ataka 1998; Morikawa et al. 1996; Oda et al. 1994). However, the validity of expressing wood color using $L^{*}$ values remained scientifically unverified. In the current study, we showed the reasonability for expressing the color using the $L^{*}$ values by methods based on numerical and visual validity. Indeed, we used $L^{*}$ data to select "typical Akajin" and "typical Kurojin" specimens. The "typical Akajin" and "typical Kurojin" specimens selected based solely on $L^{*}$ values corresponded with our visual assessment of reddish or blackish heartwood color. It can be safely said that the conventional use of $L^{*}$ as a representative index is appropriate.

This study demonstrated significant differences in wood color between genotyped clones and a moderate repeatability in this trait. The results of spatial autocorrelation analysis also indicated significant genetic effect but no significant micro-environmental effect. From these findings we showed that heartwood color is rather controlled by genetic factors when grown in a uniform environment. In addition, there were significant differences in moisture and potassium contents between "typical Akajin" and "typical Kurojin" heartwood $(p<0.01)$. The relation between moisture and potassium contents and wood color has already been reported (Oda et al. 1994; Morikawa et al. 1996; Yazawa 1964; Fujiwara and Iwagami 1988; Kawazumi et al. 1991; Hirakawa et al. 2003a, b). Our report is consistent with these previous reports. Our spatial autocorrelation analysis did not reveal an environmental effect on wood color. Therefore, if we assume that there is no difference in soil components or potassium content between any of the planted positions in this nursery, we can estimate that the movement of water and potassium into the trunk and its transfer and accumulation within the heartwood is genetically regulated and that accumulated water and potassium within the heartwood has some impact on its color.

In contrast, there are some clones comprising individuals with rather different heartwood colors. As a possible cause of this, differences in propagation methods were considered, in addition to the microtopographic or microenvironmental influence as mentioned above or an artificial measurement error. It is possible that grafting may affect the absorption of moisture and potassium because the rootstock part is genetically different from the trunk and that this may affect the heartwood color. However, when the repeatability of clones was compared between groups with two different propagation methods, we did not find a considerable difference or trend. Based on this fact, the effect of propagation methods on heartwood color could be regarded as limited. Therefore, it should be possible to obtain greater or smaller proportions of desirably colored wood by selecting clones for planting, regardless of the propagation method.

Immediately after logging, the differences in heartwood color between "typical Akajin" and "typical Kurojin" are clear. The ranking of each index of the clones did not greatly change after long periods of preservation, and there was a significant difference between the two typical groups in all color indices after preservation as well. After long-term preservation without any artificial drying or treatment, however, color differences are generally diminished. The $L^{*}$ value, i.e., the lightness, of "typical Kurojin" greatly increased over a long period of storage, exceeding the value of "typical Akajin" as measured just after logging; therefore, we conclude that the heartwood color is quite bright in both "typical Akajin" and "typical Kurojin." Differences in $a^{*}$ and $b^{*}$ values after long-term conservation were also greatly decreased compared with those seen in fresh wood. It can be said that what is regarded as an apparent defect of "Kurojin" can be naturally overcome to some extent by long-term storage, making it merely a costly defect rather than a fatal one.

The results of this study shed new lights on the characteristics, potential uses, and breeding of wood. As it turns out, the color of a fresh log is a temporary trait and may be of low importance. Although the variation range becomes smaller after preservation, we found that the color immediately after logging has a strong correlation with the color after drying. That is to say, the color remains reddish even after long preservation if it is originally reddish. In addition, we focused on the relationship of color with moisture content, which determines the drying process. Previous reports and this study also showed that $L^{*}$, i.e., the brightness of the fresh logs, is related to moisture content and that it is a heritable trait with high clonal repeatability. Therefore, we can estimate moisture content to some extent based on color. There have been some reports regarding extractives and carbon content in the heartwood as well for this species (Tamura et al. 2005). In these reports, extractives and carbon content are shown to be traits with high heritability but low variation. Particularly for carbon content, variation was very small. Compared with these two traits, heartwood color has more variation, from reddish to blackish. Further, because wood color, unlike these two traits, is a visible trait, there is a somewhat larger market for the red heartwood color for esthetic reasons (Kansai Regional Breeding Office, Forest Tree Breeding Center, 1977). Therefore, although it may not be a positive way of breeding, it should be possible to produce value-added wood by incorporating heartwood color into the ordinary breeding criteria such as growth. For example, when we develop new lines that are superior in growth, we can secondarily sieve them using heartwood color as a criterion. Alternatively, because this study has demonstrated a rather strong genetic effect, we have the option of planting clones with reddish heartwood propagated by either cutting or grafting, taking advantage of the direct genetic effect.

Because the potential effects of genetic and environmental interactions are unknown, we cannot yet predict the heartwood color of trees planted in different environments. 
Therefore, we are now planning an investigation on the responses of different clones to soil with various potassium contents and the detection of potassium in parts of individual trees, both within the heartwood and outside the heartwood. This plan is expected to enable the strict separation of genetic and environmental effects and the evaluation of $\mathrm{G} \times \mathrm{E}$ interaction in heartwood color and will also help in understanding the movement of potassium within plants.

\section{Acknowledgement}

MN coordinated the research project. IK carried out experimental analysis in the laboratory. $\mathrm{YH}$ managed the research material and data. NJ carried out data analysis. This work was supported by JSPS KAKENHI Grant Number 15K07494.

\section{References}

Abe Z, Oda K (1994) The color change of Sugi (Cryptomeria japonica) heartwood from reddish brown to black II. Identification of potassium hydrogen carbonate as one of the causative materials. Mokuzai Gakkaishi 40(10): 11261130

Color Dream Net (2013) "Irodashi Meijin Pro" for Windows ver.1.01.

Endo K, Takahashi H, Kikuchi N (2001) Research for the effective usage of black-heartwood Sugi (Cryptomeria japonica). Bulletin of the Fukushima Prefectural Forestry Research Centre 34:163-174. (This title is a tentative translation from the original Japanese by the author of this paper)

Forestry Agency Guidance Department (1994) Notices related to forest tree breeding business (This title is a tentative translation from the original Jap anese by the author of this paper)

Forestry and Forest Products Research Institute (2004) Ten points for drying in Cryptomeria japonica. https://www.ffpri.affrc.go.jp/pubs/chukiseika/documents/1st-chukiseika-18.pdf. [quoted 11.05.2016]

Forest Tree Breeding Center, Forestry Agency, Ministry of Agriculture, Forestry and Fisheries (1998) Report on Characteristic evaluation for forest tree genetic resources No.1 (This title is a tentative translation from the original Japanese by the author of this paper)

Fujisawa Y, Ohta S, Nishiura K, Toda T, Tajima M (1995) Variation in moisture contents of heartwood among clones and test stands in Sugi (Cryptomeria japonica). Mokuzai Gakkaishi 41(3):249-255.

Fujiwara S, Iwagami S (1988) The moisture content in the living stem of Sugi and Hinoki. Research Reports of Kochi University 37:169-178.

Hirakawa Y, Fujisawa Y, Nakada R, Yamashita K (2003a) Wood properties of Sugi clones selected from plus trees in Kanto breeding region. Bulletin of the Forestry and Forest Products Research Institute 2(1):31-41.

Hirakawa Y, Fujisawa Y, Nakada R, Yamashita K (2003b) Analyzed Data relative to wood properties of Sugi clones selected from plus trees in Kanto breeding region. Bulletin of the Forestry and Forest Products Research Institute 2(1):65-74.

Kansai Regional Breeding Office, Forest Tree Breeding Center (1977) Study on the heartwood color of Japanese cedar. Forest Tree Breeding 105:17-20. (This title is a tentative translation from the original Japanese by the author of this paper)

Kawazumi K, Oda K, Tsutsumi J (1991) Heartwood properties of Sugi (Cryptomeria japonica): Moisture content of green wood, hot water extractives and lightness. Bulletin of the Kyushu University Forests 64:29-39.

Kitamura Y (1962) On the black-stained heartwood of Cryptomeria japonica D. Don, Bulletin of the Forestry and Forest Products Research Institute 146:133-142.

Kubo T, Akata S (1998) Blackening of Sugi (Cryptomeria japonica D. Don) heartwood in relation to metal content and moisture content. J Wood Sci 44:137141.

Kurinobu S, Yomogida H, Yamaguchi K (1992) Moisture content, heart-wood color and wood-specific gravity of plus-tree clones of Sugi (Cryptomeria japon- ica) measured at clone-banks. Annual Report 1990, Kanto Forest Tree Breeding Institute 24:7-24.

Kuroda K (2006) Causes and countermeasures to black-heartwood Sugi (Cryptomeria japonica). Wood Industry 61(12):611-613. (This title is a tentative translation from the original Japanese by the author of this paper)

Miyamoto N, Ono M, Watanabe A (2015) Construction of a core collection and evaluation of genetic resources for Cryptomeria japonica (Japanese cedar). J For Res 20(1):186-196. Available at https://doi.org/10.1007/s10310-014$\underline{0460-3}$

Moran PAP (1950) Notes on continuous stochastic phenomena. Biometrika 37 (1): 17-23.

Morikawa T, Oda K, Matsumura J, Tsutsumi J (1996) Black-heartwood formation and ash content in the stem of Sugi (Cryptomeria japonica D. Don) II: Heartwood properties of three Sugi cultivars. Bulletin of the Kyushu University Forests 74:41-49.

Nakada R (2007) Variation of water distribution within living stems and its causal factors in Cryptomeria japonica (L. f.) D. Don. Bulletin of Forest Tree Breeding Center 23:121-254.

Nishizawa E, Gyokusen K, Hosaka T (2003) Effects of potassium content in heartwood and soil on heart-wood color of slope planted Sugi (Cryptorneria japonica D. Don). Journal of the Japanese Forestry society 85: 234-236.

Ohba K, Nishimura K, Toda T, Matsunaga K, Ohkubo T (1977) Breeding for heartwood color of Cryptomeria japonica. Forest Tree Breeding 105:25-30. (This title is a tentative translation from the original Japanese by the author of this paper)

Oda K, Matsumura J, Tsutsumi J, Abe Z (1994) Black-heartwood formation and ash contents in the stem of Sugi (Cryptomeria japonica D. Don). Science bulletin of the Faculty of Agriculture, Kyushu University. 48(3):171-176.

R Core Team (2013) R: A language and environment for statistical computing. $R$ Foundation for Statistical Computing, Vienna, Austria. http:// www.R-project.org/. [quoted 11.05.2016]

Sekimoto H, Yamada T, Hotsuki T, Fujiwara T, Mimura T, Matsuzaki A (2014) Evaluation of the radio-active $\mathrm{Cs}$ concentration in brown rice based on the $\mathrm{K}$ nutritional status of shoots. J Plant Res 127:73-78. Available at https://doi. org/10.1007/s10265-013-0614-y

Tamura A, Fujisawa Y, lizuka K, Kubota M (2005) Influence of heartwood extractives on carbon content variations among clones in the heartwood of Sugi (Cryptomeria japonica) Mokuzai Gakkaishi 51(4): 257-264.

Worrall J J, Parmeter J J R (1982) Formation and properties of wetwood in white fir. Phytopathology and Biochemistry 72(9):1209-1212.

Yazawa K (1964) Moisture contents distribution within stems. Northern forestry 187:309-314. (This title is a tentative translation from the original Japanese by the author of this paper) 